\title{
Analysis of Long-Term Morbidity of Syphilis in the Republic of Sakha (Yakutia)
}

\author{
Lyubov I. Petrova, $\mathrm{PhD}^{1}$; Snezhana S. Sleptsova, $\mathrm{PhD}, \mathrm{ScD}^{1 *}$; Anastasia N. Petrova ${ }^{1}$; \\ Spiridon S. Sleptsov, $\mathrm{PhD}^{2}$ \\ ${ }^{1}$ M. K. Ammosov North-Eastern Federal University \\ ${ }^{2}$ Yakut Science Centre of Complex Medical Problems \\ Yakutsk, the Sakha Republic, Russia
}

\begin{abstract}
This article presents the data from an analysis of the epidemiological situation on the incidence of syphilis in the Republic of Sakha (Yakutia) (RS(Y)) for the period between 1982 and 2017. The highest incidence of syphilis in RS(Y) was in 1997, 1998, 1999 (253.9, 296.2, 258.6 per 100,000 population, respectively), which coincided with the socio-economic transformations in society. Currently, there is a decrease in syphilis morbidity. Nevertheless, the high rate of late latent forms requires epidemiological monitoring. (International Journal of Biomedicine. 2020;10(3):278-280.)
\end{abstract}

Key Words: syphilis $\bullet$ morbidity $\bullet$ epidemiology $\bullet$ Yakutia

\section{Introduction}

Sexually transmitted infections (STIs) represent a major public health crisis worldwide. The importance of this problem is due not only to the spreading of STIs but also to severe complications, such as infertility, pathology of pregnancy, and childbirth: miscarriage, premature birth, and infant mortality. Reproductive pathology is one of the reasons for the low birth rate, which affects the growth of the population. The greatest damage is caused by the late forms of syphilis with lesions of internal organs and nervous system, which are associated with diagnostic difficulties, severity, difficulties of treatment, and longer time needed to observe patients. ${ }^{(1-4)}$

The purpose of this study was to assess the features of the syphilis spread during more than 35 years in the Republic of Sakha (Yakutia) (RS(Y)).

\section{Materials and Methods}

The sources of information were the data from the Yakut Medical Information-Analytical Center of the Ministry of Health of the Republic of Sakha (Yakutia), the Yakut Republican Dermato-Venerologic Center, in the period from 1982 to 2017, presented as State reporting forms No9 and No34.

\section{Results and Discussion}

The morbidity due to syphilis in $\mathrm{RS}(\mathrm{Y})$ in the studied period was characterized as extremely unsteady. There were three peaks in the incidence, which were different in duration, level, growth, and decline time. Peak 1 was registered in 1984-1987, Peak 2 - in 1994-2001, and Peak 3 - in 2008-2015 (Fig.1).

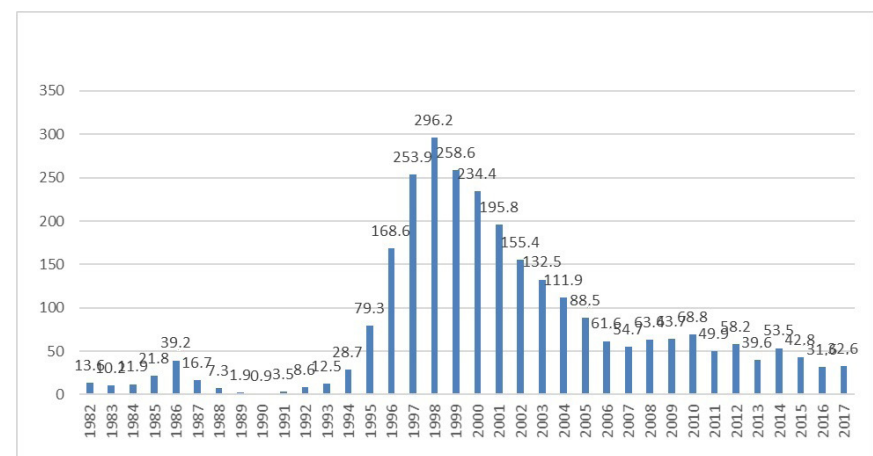

Fig. 1. Three peaks in the incidence of syphilis in $R S(Y)$.

Peak 1 was characterized by low intensity and duration. The highest incidence was recorded in 1986 (an intensive rate of 39.2 per 100,000 population), with a minimum in 1983 - 
10.2 per 100,000 population. From 1988 to 1992 , there was a decrease in the incidence.

The morbidity rate in 1990 was 0.9 per 100,000 population. In 1992, new growth in morbidity was registered (8.6 per 100,000 population), which lasted until 2000. From 1994 to 1998 , the morbidity rate rose and reached its highest rate by 1998 (296.2 per 100,000 population). In comparison with 1990 (year of minimal syphilis incidence), in 1998 that indicator was increased by 329.1 times. Thus, 1992-2000 is assessed as an epidemic of syphilis with a progressive increase in the incidence rate.

Statistical data from 1990-2000 were analyzed to compare the dynamics of syphilis incidence in $\mathrm{RS}(\mathrm{Y})$ with that of the Russian Federation (Table 1). The epidemic increase in the syphilis incidence in Russia has been noted since 1990, with a rapid increase in 1993 (growth rate of $153.0 \%$ ). In 1997, the incidence rate reached 277.3 cases per 100,000 population, which was 64 times more than in 1988. In 1997, the increase rate slowed down and stabilized; finally, in 1998, the morbidity level started to decrease (Table 1).

Table 1.

Dynamics of syphilis morbidity in the Russian Federation and $R S(Y)$ in 1990-2000

\begin{tabular}{|c|c|c|c|c|}
\hline \multirow{2}{*}{ Year } & \multicolumn{2}{|c|}{ Russian Federation } & \multicolumn{2}{c|}{ RS(Y) } \\
\cline { 2 - 5 } & $\begin{array}{c}\text { Morbidity rate } \\
\text { per 100,000 }\end{array}$ & Growth rate & $\begin{array}{c}\text { Morbidity rate } \\
\text { per 100,000 }\end{array}$ & Growth rate \\
\hline 1990 & 5.4 & $+25.6 \%$ & 0.9 & $-52.6 \%$ \\
\hline 1991 & 7.2 & $+33.3 \%$ & 3.5 & $+28.9 \%$ \\
\hline 1992 & 13.4 & $+86.1 \%$ & 8.6 & $+14.6 \%$ \\
\hline 1993 & 33.9 & $+153.0 \%$ & 12.5 & $+54.3 \%$ \\
\hline 1994 & 85.8 & $+153.1 \%$ & 28.7 & $+129.6 \%$ \\
\hline 1995 & 177.0 & $+106.3 \%$ & 79.3. & $+176.3 \%$ \\
\hline 1996 & 264.6 & $+49.5 \%$ & 168.6 & $+112.6 \%$ \\
\hline 1997 & 277.3 & $+4.8 \%$ & 253.9 & $+50.5 \%$ \\
\hline 1998 & 234.8 & $-15.3 \%$ & 296.2 & $+16.7 \%$ \\
\hline 1999 & 187.2 & $-20.3 \%$ & 258.6 & $-12.7 \%$ \\
\hline 2000 & 165.7 & $-11.5 \%$ & 234.4 & $-9.4 \%$ \\
\hline
\end{tabular}

Syphilis morbidity in $\mathrm{RS}(\mathrm{Y})$ repeated the incidence plot in the Russian Federation with a lag of two years. The rates of growth and reduction of syphilis morbidity in $\mathrm{RS}(\mathrm{Y})$ and the Russian Federation do not differ significantly (Fig.2).

Peak 3 of syphilis morbidity was characterized by a wave-like course. The highest rate was recorded in 2010 (68.8 per 100.000 population), with a decrease in 2013 (39.6 per 100.000 population). Due to the measures taken to control STIs, a high rate of reduction in the incidence of syphilis was achieved, and in 2016 the morbidity rate dropped to 31.6 per 100,000 population. The current decrease in syphilis morbidity does not yet indicate full epidemiological well-being. This decrease was accompanied by changes in the structure of clinical forms in the direction of increasing the latent forms.
Analysis of acquired syphilis form structure showed that the proportion of early latent forms increased, compared to the primary and secondary periods of syphilis. Thus, in 2013, the incidence of early latent syphilis was 19.1, and of primary and secondary -20.2 . There was also an increase in late latent forms and reported cases of neurosyphilis. In 2013, the late latent syphilis was 0.1 per 100,000 population; in $2017-1.8$ per 100,000 population, and neurosyphilis -0.3 per 100,000 population. Thus, there was an increase in the incidence of late latent forms of syphilis, especially neurosyphilis. These were characterized by severe clinical presentation, lesions of organs and nervous system primarily latent or with an erased clinical picture, the formation of seroresistance, and delayed negativization of serological reactions after the end of the treatment of patients with syphilis, all of which caused concern among specialists.

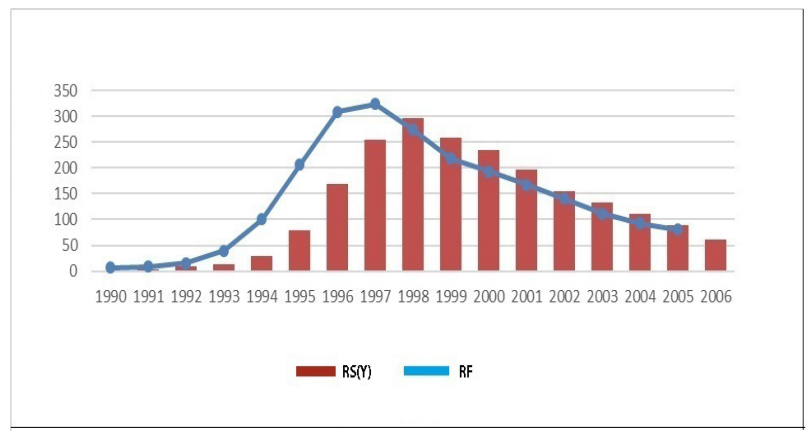

Fig. 2. The rates of growth and reduction of syphilis morbidity in $R S(Y)$ and the Russian Federation

The analysis of the long-term dynamics of the syphilis morbidity in $\mathrm{RS}(\mathrm{Y})$ revealed the uniqueness of the epidemic of syphilis in 1993-2000, which coincided with social and economic transformations. Negative, stressful life events, such as unemployment, the growth of prostitution, drug addiction and crime, were associated with a significantly pronounced intensity (12.2 - 296.2 cases per 100.000 population) and the growth rate of syphilis morbidity (up to $329.1 \%$ ). During Peak 3 of syphilis morbidity, the incidence rate in 2010 (68.6 per 100.000 population) was significantly higher than in 1993 (12.5 per 100.000 population). With an increase in the incidence of syphilis, the number of patients with early forms of the disease increased sharply, with a decrease - the proportion of patients with late latent forms of damage to the nervous system and internal organs increased. Studies of the past 5 years have shown a high proportion of late latent syphilis and neurosyphilis.

Thus, syphilis remains as relevant a problem as it was many centuries ago. The important part in preventing this infection is further improvement of the system of providing prompt, reliable and confidential information to the population, especially the young people, about the danger of syphilis

*Corresponding author: Prof. Snezhana S. Sleptsova, MD, PhD, ScD. M. K. Ammosov North-Eastern Federal University. Yakutsk, the Sakha Republic,Russia.E-mail: sssleptsova@yandex.ru 
and other STIs and ways of prevention, as well as measures against alcoholism and drug addiction, and full coverage of the population with preventive examinations.

\section{Competing Interests}

The authors declare that they have no competing interests.

\section{References}

1. Kubanova AA, Kubanov AA, Melekhina LE. [Incidence of Syphilis in the Russian Federation over the Period 2006-
2016]. Vestnik Dermatologii i Venerologii. 2017;93(5):16-25. [Article in Russian].

2. Kubanova AA, Kubanov AA, Melekhina LE, Bogdanova VE. [Syphilis incidence rate in the Russian Federation in 20102014]. Vestnik Dermatologii i Venerologii. 2015;91(5):15-23. [Article in Russian].

3. Kungurov NV, Hal'fin RA, Syrneva TA, Marchenko NV. Experience of organizing the fight against syphilis in the constituent entity of the Russian Federation. Yekaterinburg: publishing house: "Charoid"; 2002.(In Russian].

4. Mandelbrot L, Marcollet A. [Syphilis and pregnancy]. Rev Prat. 2004;54(4):392-395. [Article in French]. 